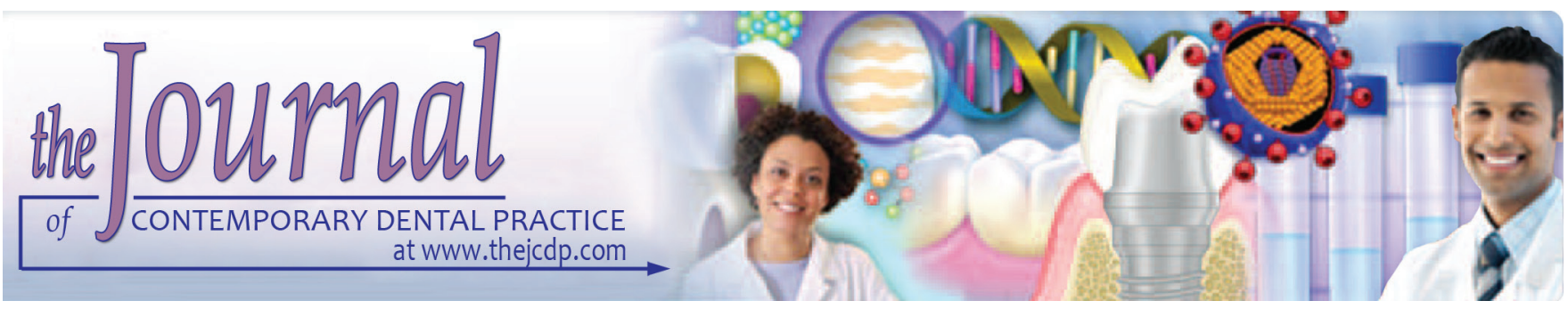

\title{
Accuracy of Three Shade-matching Devices in Replicating the Shade of Metal Ceramic Restorations: An in vitro Study
}

\author{
${ }^{1}$ Shruti Lakhanpal, ${ }^{2}$ Menon S Neelima
}

\begin{abstract}
Introduction: In restorative dentistry, the clinician commonly encounters the challenge of replicating the color of natural teeth due to the subjectivity of perceptual evaluation. Recent advances in photography and computing have resulted in the widespread use of the digital camera for color imaging. These instruments can be used effectively for shade matching and communication to yield predictable results.
\end{abstract}

Materials and methods: The study sample consisted of 20 freshly extracted noncarious premolars. The Commission Internationale de l'Eclairage (CIE) $L^{*} a^{*} b *$ values of the tooth were obtained through a spectrophotometer, digital camera, and digital camera with a polarizer. Shade selection was carried out using VITA 3D Master and calculating the Euclidian distance. The fabricated metal ceramic crowns were then evaluated to check the shade replication by comparing the $\operatorname{CIE~} L^{*} a{ }^{*} b^{*}$ values of the crowns with the reference shade tab images.

Results: The three-way analysis of variance (ANOVA) and comparative analysis using Bonferroni test reveals that the difference in the mean $L^{*} a^{*}$ values between spectrophotometer and polarization dental imaging modality (PDIM) was insignificant. The difference in the mean $L^{*} a^{*} b^{*}$ of spectrophotometer and digital camera was statistically significant. The mean $\Delta E$ for metal ceramic crowns and shade tabs was 4.2 that was greater than the clinically acceptable level (3.2).

Conclusion: A statistically significant correlation was found to exist between the spectrophotometer and PDIM for all CIE $L^{*}$, $a^{*}$, and $b^{*}$ color coordinates.

Clinical significance: The present study was undertaken to assess the shade-matching ability of three shade-matching

${ }^{1}$ Department of Prosthodontist, Clove Dental, Delhi, New Delhi, India

${ }^{2}$ Department of Prosthodontics and Implantology, P.S.M. College of Dental Science and Research, Akkikavu, Thrissur, Kerala

Corresponding Author: Menon S Neelima, Department of Prosthodontics and Implantology, P.S.M. College of Dental Science and Research, Akkikavu, Thrissur, Kerala, Phone: +919447839034, e-mail: drneelimaprosthodontist@gmail.com devices, such as spectrophotometer, digital camera, and PDIM, in the accuracy of replication of metal ceramic restorations.

Keywords: Digital camera, Polarizer, Shade matching, Spectrophotometer.

How to cite this article: Lakhanpal S, Neelima MS. Accuracy of Three Shade-matching Devices in Replicating the Shade of Metal Ceramic Restorations: An in vitro Study. J Contemp Dent Pract 2016;17(12):1003-1008.

\section{Source of support: Nil}

Conflict of interest: None

\section{INTRODUCTION}

In restorative dentistry, the clinician commonly encounters the challenge of replicating the color of natural teeth. The goal of an esthetic restoration is to achieve morphological, optical, and biological beauty, which results in social acceptance.

The perception of tooth color is a complex phenomenon and can be influenced by a number of factors, including the type of incident light, the reflection and absorption of light by the tooth, the adaptation state of the observer, and the context in which the tooth is viewed. ${ }^{1}$

The conventional method of evaluating tooth color is visual observation by the naked eye; however, it is impossible to obtain objective color information by this method. Color measurement devices, such as colorimeters and optical spectrometers, have been used in dentistry in order to acquire quantitative color information for a specific narrow region. However, these devices do not provide image information and might have motion artifacts caused by handpiece-type probes. The small (usually $3 \mathrm{~mm}$ ) window of the devices may not capture reliably the real color information of the whole tooth surface. The second shortcoming is the improper measurement of the curved translucent surfaces found on teeth using the contact-type instruments that are designed for flat surfaces. ${ }^{2}$ The third shortcoming is that most of these equipments employ 
mean values or intensity histograms for representing the shade zone for color labeling and ignore the geometric distribution of color within the region. ${ }^{3}$

The final color matching of porcelain crowns depends on the accuracy of the original shade matching by the dentist and variables introduced during processing. Recently, the usage of megapixel digital cameras has been widely adopted in the fields of dentistry.

Although the digital color imaging modality provides image information, the specular reflection caused by saliva or roughness on the tooth surface might cause artifacts in image analysis. ${ }^{4}$

Polarization dental imaging modality (PDIM) and image analysis methods address the limitations of the currently available methods. Unlike colorimeters, optical spectrometers, and digital color cameras, PDIM provides both quantitative and qualitative information on tooth color and minimizes motion artifact during image acquisition. Its primary advantage is to provide tooth color images that eliminate specular reflection from the tooth surface. ${ }^{5}$

Hence, the present study was undertaken to assess the shade-matching ability of three shade-matching devices, i.e., spectrophotometer, digital camera, and PDIM, through in vitro replication of the shade matching of metal ceramic crowns.

\section{MATERIALS AND METHODS}

Twenty freshly extracted, sound, noncarious permanent premolars were used for the study.

\section{Methodology}

\section{Preparation of the Samples for Study}

The specimens were scaled to remove any surface deposits. The teeth specimens were embedded in pink autopolymerizing acrylic resin model for the purpose of imaging.

\section{Imaging Process and Obtaining CIE L* $a^{*} b^{*}$ Values}

The color of the tooth samples was measured by obtaining the $L^{*} a^{*} b^{*}$ values of the middle third of the tooth sample using a spectrophotometer.

Imaging process: The PDIM consisted of Canon EOS $1100 \mathrm{D}$ camera, a ring-shaped light-emitting diode flash (Meike FC100), two circular polarizers (Hoya $52 \mathrm{~mm}$ ), and macrolens (Canon EFS 18-55 mm) (Fig. 1).

For the purpose of obtaining images, the tooth samples were photographed in a dark room setup. The cameras were fixed on the tripod with the focus positioned to measure the same sample area as the spectrophotometer. The camera was set on auto mode. The camera's position to the sample was minimized so as to maximize the pixels of the samples. Each camera was used to take a total of 40 images (in raw format). ${ }^{6}$

Therefore, a total of 40 images were obtained by using a digital camera both with polarizer (Fig. 2) and without a polarizer (Fig. 3).

The images were analyzed by using MATLAB software to obtain the Commission Internationale de $l^{\prime}$ Eclairage (CIE) $L^{*} a^{*} b^{*}$ values in which the standard observer was 2-degree observer, and illumination was International Color Consortium standard profile connection space illuminant with a 16-bit fractional approximation of D50. ${ }^{5}$ A $4 \mathrm{~mm}$ square of each image was then cropped to standardize the sample areas measured by the spectrophotometer. The $L^{*} a^{*} b^{*}$ values were obtained for each of the 40 cropped images.

The CIE $L^{*} a^{*} b^{*}$ values obtained through spectrophotometer Datacolor 650 (Fig. 4), digital single-lens reflex camera, and digital camera with a polarizer were subjected to statistical analysis, and the most reliable device was selected for further shade matching.

\section{RESULTS}

The $L^{*} a^{*} b^{*}$ values were subjected to analysis of variance (ANOVA) test.
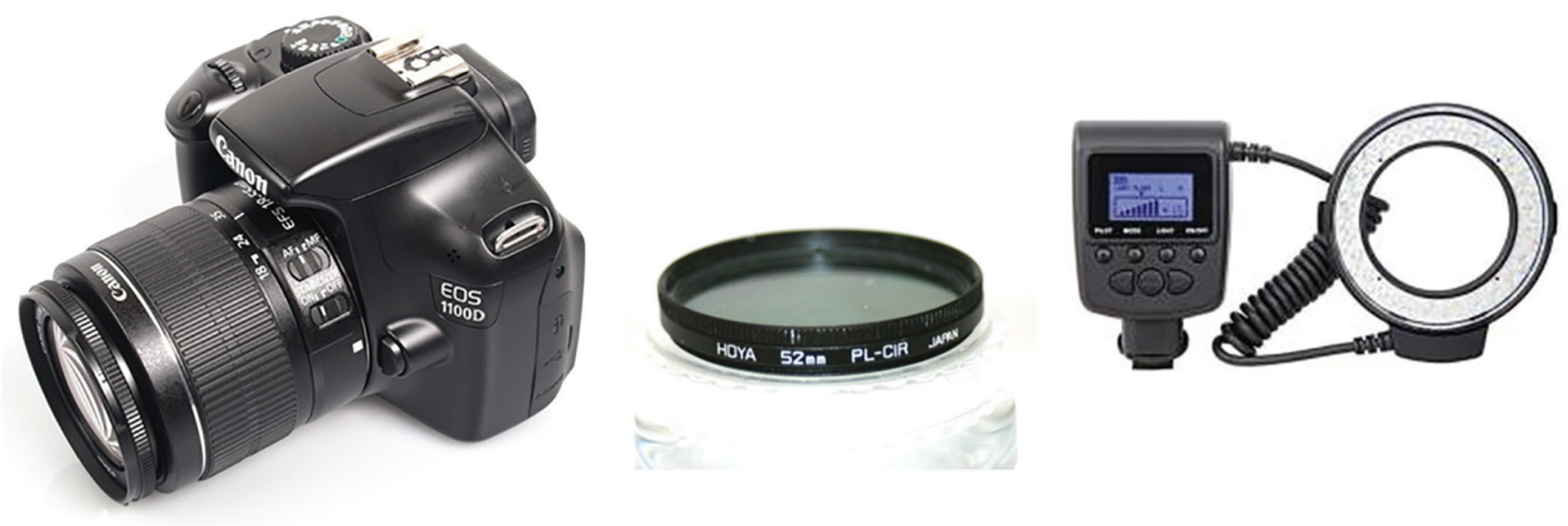

Fig. 1: Canon EOS 1100D with 12-55mm Macro lens, Hoya 52mm polarizer and Ring flash 


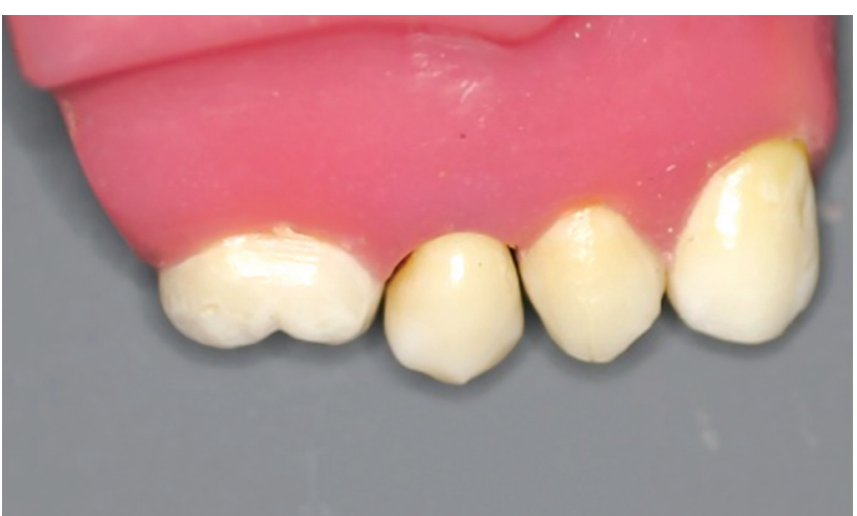

Fig. 2: Polarized image

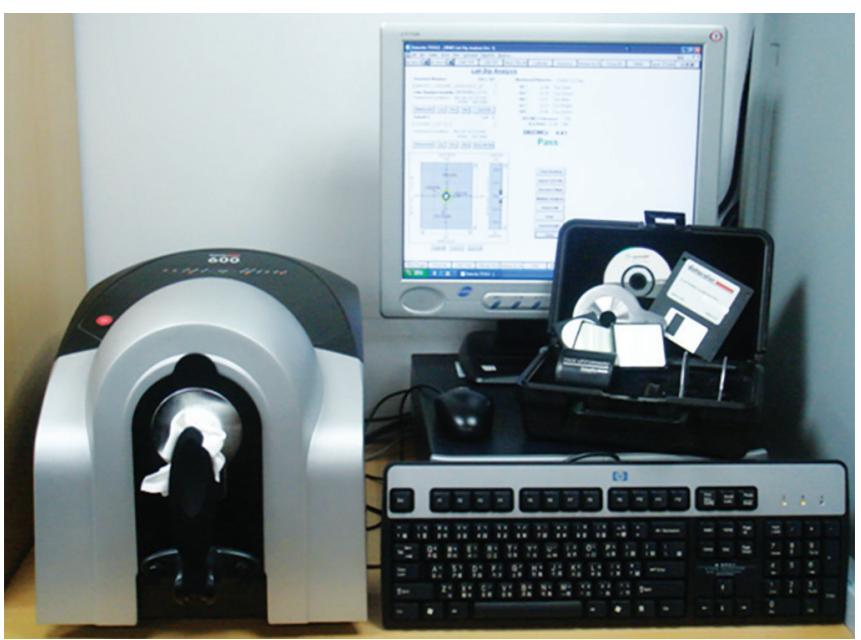

Fig. 4: Datacolor 650 spectrophotometer

The difference in mean $L^{*}$ values was found to be statistically significant between the spectrophotometer and digital camera $(\mathrm{p}<0.001)$ as well as between polarizer with digital camera and digital camera $(\mathrm{p}<0.001)$.

No significant difference was observed between spectrophotometer and polarizer with digital camera $(\mathrm{p}>0.05)$.

The difference in mean $a^{*}$ values was found to be statistically significant between spectrophotometer and digital camera $(\mathrm{p}<0.001)$ as well as between polarizer with digital camera and digital camera $(\mathrm{p}<0.001)$.

No significant difference was observed between spectrophotometer and polarizer.

The difference in mean $b^{*}$ values recorded among the groups was not statistically significant $(p>0.05)$.

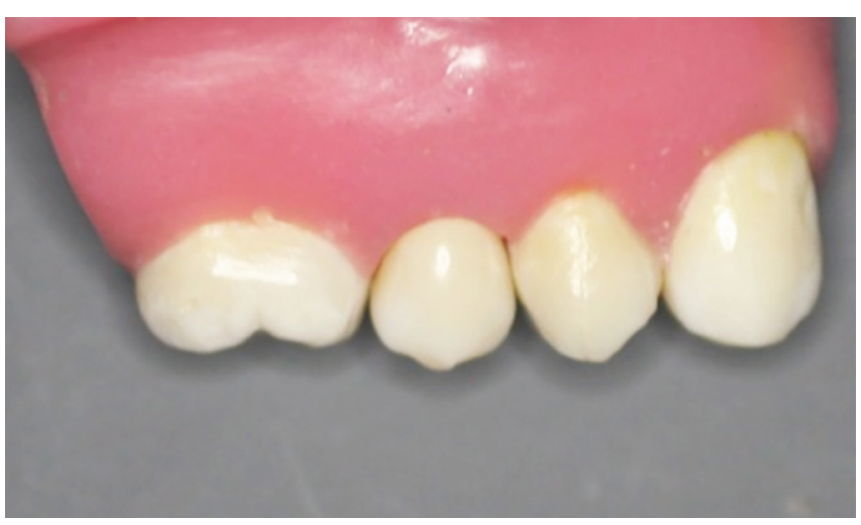

Fig. 3: Non-Polarized image

The $L^{*} a^{*} b^{*}$ values of the shade tabs and porcelainfused-to-metal (PFM) crowns were compared with Mann-Whitney test.

The mean $\Delta E$ for the PFM crowns and shade tabs was 4.2 .

\section{DISCUSSION}

The primary goal of esthetic dentistry is to provide functional and natural-appearing dental restorations for the patients. This study describes a PDIM that uses the principle of cross-polarization to minimize the specular reflection from the tooth surface, thereby avoiding artifacts in image analysis. ${ }^{5}$

Color difference or $\Delta E$ is defined by the following equation:

$$
\Delta E=\left[\Delta L^{* 2}+\Delta a^{* 2}+\Delta b^{* 2}\right]^{1 / 2}
$$

Here $\Delta L^{*}, \Delta a^{*}$, and $\Delta b^{*}$ are the respective differences between the measured and predicted CIE LAB values of the shade tabs.

The $L^{*} a^{*} b^{*}$ values obtained from the three shadematching devices were compared and assessed.

Tables 1 to 3 depict the comparison of $L^{*}$ values obtained through spectrophotometer, digital camera, and PDIM.

There was statistically significant difference between the $L^{*}$ values of spectrophotometer and digital camera. However, the difference between PDIM and spectrophotometer was statistically insignificant.

The statistically significant results of $L^{*}$ values of spectrophotometer and digital camera may originate from the

Table 1: Comparison of $L^{*}$ values

\begin{tabular}{|c|c|c|c|c|c|c|c|}
\hline \multirow[b]{2}{*}{ Device } & \multirow[b]{2}{*}{ Mean } & \multirow{2}{*}{$\begin{array}{l}\text { Standard } \\
\text { deviation }\end{array}$} & \multirow[b]{2}{*}{ SE of mean } & \multicolumn{2}{|c|}{ 95\% confidence interval for mean } & \multirow[b]{2}{*}{ Min } & \multirow[b]{2}{*}{ Max } \\
\hline & & & & Lower bound & Upper bound & & \\
\hline Spectrophotometer & 81.94 & 2.20 & 0.49 & 80.91 & 82.97 & 76.87 & 85.55 \\
\hline Polarizer with digital camera & 82.41 & 2.82 & 0.63 & 81.09 & 83.73 & 76.34 & 88.90 \\
\hline Digital camera & 88.97 & 2.02 & 0.45 & 88.03 & 89.92 & 85.15 & 93.14 \\
\hline
\end{tabular}


Table 2: Analysis of variance test

\begin{tabular}{llllll}
\hline Source of variation & $d f$ & Sum of squares (SS) & Mean SS & $f$-value & $p$-value \\
\hline Between groups & 2 & 618.336 & 309.168 & 55.040 & $<0.001^{*}$ \\
Within groups & 57 & 320.178 & 5.617 & - & - \\
\hline Total & 59 & 938.514 & - & - & - \\
\hline
\end{tabular}

*significance $p$ value $<0.001$, indicating the statistically significant result

Table 3: Bonferroni test

\begin{tabular}{|c|c|c|c|c|c|}
\hline \multirow[b]{2}{*}{ (I) Device } & \multirow[b]{2}{*}{ (J) Device } & \multirow[b]{2}{*}{ Mean difference $(I-J)$} & \multirow[b]{2}{*}{$p$-value } & \multicolumn{2}{|c|}{$\begin{array}{c}95 \% \text { confidence interval for } \\
\text { mean difference }\end{array}$} \\
\hline & & & & Lower bound & Upper bound \\
\hline \multirow[t]{2}{*}{ Spectrophotometer } & Polarizer with digital camera & -0.475 & 1.000 & -2.32 & 1.37 \\
\hline & Digital camera & -7.035 & $<0.001^{*}$ & -8.88 & -5.19 \\
\hline \multirow[t]{2}{*}{ Polarizer with digital camera } & Spectrophotometer & 0.475 & 1.000 & -1.37 & 2.32 \\
\hline & Digital camera & -6.560 & $<0.001^{*}$ & -8.41 & -4.71 \\
\hline \multirow[t]{2}{*}{ Digital camera } & Spectrophotometer & 7.035 & $<0.001^{*}$ & 5.19 & 8.88 \\
\hline & Polarizer with digital camera & 6.560 & $<0.001^{*}$ & 4.71 & 8.41 \\
\hline
\end{tabular}

*significance $p$ value $<0.001$, indicating the statistically significant result

Table 4: Comparison of mean $a^{*}$ values

\begin{tabular}{llllllll}
\hline & & Standard & & \multicolumn{2}{c}{ 95\% confidence interval for mean } & \\
Device & Mean & deviation & SE of mean & Lower bound & Upper bound & Min & Max \\
\hline Spectrophotometer & 0.77 & 1.33 & 0.30 & 0.15 & 1.39 & -2.28 & 2.75 \\
Polarizer with digital camera & 0.83 & 1.34 & 0.30 & 0.20 & 1.46 & -2.28 & 2.75 \\
Digital camera & -1.33 & 1.08 & 0.24 & -1.84 & -0.83 & -3.58 & 0.80 \\
\hline
\end{tabular}

Table 5: Analysis of variance

\begin{tabular}{llllll}
\hline Source of variation & $d f$ & Sum of squares (SS) & Mean SS & $f$-value & $p$-value \\
\hline Between groups & 2 & 60.603 & 30.302 & 19.257 & $<0.001^{*}$ \\
Within groups & 57 & 89.692 & 1.574 & - & - \\
\hline Total & 59 & 150.296 & - & - & - \\
\hline
\end{tabular}

Table 6: Bonferroni test

\begin{tabular}{|c|c|c|c|c|c|}
\hline \multirow[b]{2}{*}{ (I) Device } & \multirow[b]{2}{*}{ (J) Device } & \multirow{2}{*}{$\begin{array}{l}\text { Mean difference } \\
(I-J)\end{array}$} & \multirow[b]{2}{*}{$p$-value } & \multicolumn{2}{|c|}{$\begin{array}{c}\text { 95\% confidence interval for } \\
\text { mean difference }\end{array}$} \\
\hline & & & & Lower bound & Upper bound \\
\hline \multirow[t]{2}{*}{ Spectrophotometer } & Polarizer with digital camera & -0.063 & 1.000 & -1.04 & 0.91 \\
\hline & Digital camera & 2.100 & $<0.001^{*}$ & 1.12 & 3.08 \\
\hline \multirow[t]{2}{*}{ Polarizer with digital camera } & Spectrophotometer & 0.063 & 1.000 & -0.91 & 1.04 \\
\hline & Digital camera & 2.163 & $<0.001^{*}$ & 1.18 & 3.14 \\
\hline \multirow[t]{2}{*}{ Digital camera } & Spectrophotometer & -2.100 & $<0.001^{*}$ & -3.08 & -1.12 \\
\hline & Polarizer with digital camera & -2.163 & $<0.001^{*}$ & -3.14 & -1.18 \\
\hline
\end{tabular}

*significance $p$ value $<0.001$, indicating the statistically significant result

variations of the measuring conditions, such as the reflectance of light in different analysis systems. Nonpolarized tooth color images presented various glare patterns on tooth surfaces, which may be caused by roughness or the uneven distribution of saliva on tooth surfaces; these cause artifacts in tooth color image analysis. In contrast, such glaring patterns were absent in the cross-polarized tooth color images.

Hence, PDIM eliminated the specular component of the light from the tooth surface, thereby revealing results having high correlation with spectrophotometer.
Tables 4 to 8 depict the comparison of $a^{*}$ and $b^{*}$ values obtained from a spectrophotometer, digital camera, and PDIM.

The results reveal that the difference in mean $a^{*}$ and $b^{*}$ values of spectrophotometer and digital camera was statistically significant and that of spectrophotometer and PDIM was statistically insignificant.

Therefore, the results revealed a high correlation between PDIM and spectrophotometer.

This can be attributed to the "edge-loss error," which is the incorrect color reading from the loss of a fraction 
Accuracy of Three Shade-matching Devices in Replicating the Shade of Metal Ceramic Restorations: An in vitro Study

Table 7: Comparison of mean $b^{\star}$ values

\begin{tabular}{|c|c|c|c|c|c|c|c|}
\hline \multirow[b]{2}{*}{ Device } & \multirow[b]{2}{*}{ Mean } & \multirow{2}{*}{$\begin{array}{l}\text { Standard } \\
\text { deviation }\end{array}$} & \multirow[b]{2}{*}{ SE of mean } & \multicolumn{2}{|c|}{ 95\% confidence interval for mean } & \multirow[b]{2}{*}{ Min } & \multirow[b]{2}{*}{ Max } \\
\hline & & & & Lower bound & Upper bound & & \\
\hline Spectrophotometer & 13.66 & 2.88 & 0.64 & 12.31 & 15.01 & 6.71 & 18.04 \\
\hline Polarizer with digital camera & 12.91 & 3.21 & 0.72 & 11.40 & 14.41 & 5.80 & 17.76 \\
\hline Digital camera & 16.56 & 15.90 & 3.56 & 9.12 & 24.01 & 9.00 & 82.76 \\
\hline
\end{tabular}

Table 8: Analysis of variance

\begin{tabular}{llllll}
\hline Source of variation & $d f$ & Sum of squares (SS) & Mean SS & $f$-value & $p$-value \\
\hline Between groups & 2 & 149.218 & 74.609 & 0.824 & 0.444 \\
Within groups & 57 & 5158.125 & 90.493 & - & - \\
\hline Total & 59 & 5307.343 & - & - & - \\
\hline
\end{tabular}

Table 9: Comparison of $L^{*}$ values between the two groups

\begin{tabular}{lllllll}
\hline Group & Mean & Standard deviation & SE of mean & Mean difference & z-value & $p$-value \\
\hline Shade Tab & 82.55 & 3.24 & 0.72 & 0.981 & -0.517 & 0.605 \\
PFM Crown & 81.57 & 3.79 & 0.85 & & & \\
\hline
\end{tabular}

Table 10: Comparison of $a^{*}$ values between the two groups

\begin{tabular}{lllllll}
\hline Group & Mean & Standard deviation & SE of mean & Mean difference & z-value & $p$-value \\
\hline Shade Tab & 0.09 & 1.21 & 0.27 & -0.595 & 0.239 & 0.253 \\
PFM Crown & 0.68 & 1.34 & 0.30 & & & \\
\hline
\end{tabular}

Table 11: Comparison of $b^{*}$ values between the two groups

\begin{tabular}{lllllll}
\hline Group & Mean & Standard deviation & SE of mean & Mean difference & z-value & $p$-value \\
\hline Shade Tab & 13.50 & 1.67 & 0.37 & 0.540 & 0.087 & 0.091 \\
PFM Crown & 12.96 & 1.44 & 0.32 & & & \\
\hline
\end{tabular}

of light entering the tooth. Edge losses occur during reflectance measurements of tooth sample when light is scattered within a sample beyond that part of the surface exposed to the observation system of the optical device. This may represent an advantage of using this software system in color measurement. ${ }^{7}$

However, this finding is not indicative of superiority of digital method over spectrophotometer; rather, it may present the ability of software to discriminate the color variances, particularly in $b^{*}$ values.

Tables 9 to 11 depict the comparative analysis of $L^{*} a^{*} b^{*}$ values of porcelain fused to metal crowns with $L^{*} a^{*} b^{*}$ values of the shade tabs.

The results reveal that the difference in the $L^{*} a^{*} b^{*}$ values was statistically insignificant.

However, in the present study, the mean $\Delta E^{*}$, i.e., the color difference between the shade tabs and the porcelain fused to metal crowns, was 4.2 , which was beyond the range of threshold of clinical acceptance previously reported. . $^{8-11}$

The final color matching of porcelain fused to metal crowns depends upon the accuracy of the original shade matching by the dentist and variables introduced during processing. In the present study, the number of firings, firing temperature, and the lab technician for ceramic buildup were kept constant.

Therefore, the sources of error or the limitations of this study are constrained due to factors, such as difference in pigment formulation of the Vita 3D master shade tab and fired porcelain, absence of the effect of saliva during shade matching, and laboratory-related errors that led to the higher value of $\Delta E$, which was beyond the clinically acceptable level.

The present study demonstrated that application of the digital analysis software program for color determination of shade tabs yielded results in $L^{*}, a^{*}$, and $b^{*}$ measurements that correlated with those obtained with spectrophotometer. Therefore, it may be speculated that this method appears to deserve further evaluations.

\section{CONCLUSION}

Within the limitations of this study, the following can be concluded: 
- Color measurements obtained with PDIM were in accordance with those of spectrophotometric evaluations, with respect to $L^{*}, a^{*}$, and $b^{*}$ values. A very high correlation was found to exist between the spectrophotometer and PDIM for all CIE $L^{*}, a^{*}$, and $b^{*}$ color coordinates.

- Polarization dental imaging modality can be used to provide glare-free tooth color images for both quantitative and qualitative image analysis.

- Further assessment of PDIM in determining color matching in esthetic dentistry is required, which can provide a more practical and consistent method to determine the color in dental clinics and to transmit this information to dental laboratories.

- Most crowns fabricated by the laboratory in this study, when compared with the prescribed shade tab, were above the clinical threshold for an acceptable shade match $(\Delta E$ 3.7).

\section{REFERENCES}

1. Commission Internationale de l'Eclairage (CIE). CIE Technical Re- port: Improvement to Industrial Color-Difference Evaluation. CIE Pub No 142-2001.Vienna, Austria: Central Bureau of the CIE; 2001.

2. Haywood VB, Leonard RH, Nelson CF, Brunson WD. Effectiveness, side effects, and long-term status of
Nightguard Vital bleaching. J Am Dent Assoc 1994 Sep;125: 1219-1226.

3. Okubo SR, Kanawati A, Richards MW, Childress S. Evaluation of visual and instrument shade matching. J Prosthet Dent 1998 Dec;80(6):642-648.

4. Macpherson LMD, Stephen KW, Joiner A, Schafer F, Huntington E. Comparison of a conventional and modified tooth stain index. J Clin Periodontol 2000 Nov;27(11):424-430.

5. Kim E, Son T, Lee Y, Jung B. Development of polarization dental imaging modality and evaluation of its clinical feasibility. J Dent 2012 Jul;40(Suppl 1):e18-e25.

6. Wee AG, Lindsey DT, Kuo S, Johnston WM. Color accuracy of commercial digital cameras for use in dentistry. Dent Mater 2007 Jun;22(6):553-559.

7. Cal E, Güneri P, Kose T. Comparison of digital and spectrophotometric measurements of colour shade guide. J Oral Rehabil 2006 Mar;33(3):221-228.

8. O'Brien WJ, Kay KS, Boenke KM, Groh CL. Sources of color variation on firing porcelain. Dent Mater 1991 Jul;7(3):170-173.

9. Groh CL, O'Brien WJ, Boenke KM. Differences in color between fired porcelain and shade guides. Int J Prosthodont 1992 Nov-Dec;5(6):510-514

10. Okubo SR, Kanawati A, Richards MW, Childress S. Evaluation of visual and instrument shade matching. J Prosthet Dent 1998 Dec;80(6):642-648.

11. Derbabian K, Marzola R, Donovan TE, Arcidiacono A. The science of communicating the art of esthetic dentistry. Part III: precise shade communication. J Esthet Restor Dent 2001;13(3):154-162. 